\title{
Propilparabenin Daphnia magna ve Saccharomyces cerevisiae Üzerindeki Toksik Etkilerinin Araştırılması
}

\author{
Investigation The Toxic Effects of Propylparaben on Daphnia magna and Saccharomyces \\ cerevisiae
}

Ceyhun BEREKETOĞLU ${ }^{1}$ (i)

${ }^{1}$ İskenderun Teknik Üniversitesi, Mühendislik ve Doğa Bilimleri Fakültesi, Biyomedikal Mühendisliği, 31200, Iskenderun, Hatay, Türkiye

\begin{abstract}
Öz
Parabenler, gıda, kozmetik ve ilaç gibi farklı ticari ürünlerde koruyucu olarak yaygın şekilde kullanılmaktadır. En yaygın kullanılan parabenlerden birisi olan propilparaben (PP) mikrobiyal büyümeyi engelleyerek birçok tüketici ürünün raf ömrünü uzatmaktadır. PP dahil olmak üzere parabenlerin geniş kullanımları çevrede birikimlerine sebep olmaktadır. Bu çalışmada, PP'nin Daphnia magna (D. magna) ve Saccharamyces cerevisiae (S. cerevisiae) üzerindeki olumsuz etkilerini belirlemek için toksisite analizleri yapılmıştır. Bu amaçla, D. magna yavruları (<24 saat), çok düşük konsantrasyondan $(0.01 \mu \mathrm{M})$ çok yüksek konsantrasyona $(500 \mu \mathrm{M})$ kadar değişen çeşitli PP konsantrasyonlarına 48 saat boyunca maruz bırakılmış ve PP'nin sağkalım üzerindeki etkisi ve $\mathrm{LC}_{50}$ değerleri incelenmiştir. Buna göre, $100 \mu \mathrm{M}$ ve üzeri PP konsantrasyonlarının $D$. magna'da yüksek seviyede toksik olduğu belirlenmiștir. LC50 değerleri 24 ve 48 saat maruziyetleri için sırasıyla $58 \mu \mathrm{M}$ ve $49.3 \mu \mathrm{M}$ olarak bulunmuştur. Diğer taraftan, farklı PP konsantrasyonlarının (10, 50, 100, 400, 800 ve $1000 \mu \mathrm{M}$ PP) S. cerevisiae'ye olan etkileri büyüme kinetiği ve hücreler üzerindeki inhibisyon seviyeleri incelenerek belirlenmiştir. Büyüme kinetiğinde $100 \mu \mathrm{M}$ PP'ye kadar olan konsantrasyonlarda herhangi bir etki gözlemlenmezken, daha yüksek konsantrasyonlarda büyüme kinetiğinde belirgin bir düşüş tespit edilmiştir. Bununla birlikte konsantrasyon arttıkça hücre inhibisyonunda artış gözlemlenmiştir. PP'nin iki model organizmadaki etkileri karşılaştırıldığında D. magna'da daha yüksek toksisite tespit edilmiştir. Genel olarak, bu çalışma, PP'nin olumsuz etkileri hakkında önemli bilgiler sağlamış ve parabenlerle ilişkili toksisitenin moleküler mekanizmasını keşfetmek için daha fazla araştırmanın gerekliliğini ortaya koymuştur.
\end{abstract}

Anahtar Kelimeler: Propilparaben, toksisite, D. magna, S. cerevisiae, $\mathrm{LC}_{50}$

\begin{abstract}
Parabens are widely used as a preservative in different commercial products such as food, cosmetics and pharmaceuticals. Propylparaben (PP), one of the most widely used parabens, prevents microbial growth and extends the shelf life of many consumer products. The wide use of parabens, including PP, causes their accumulation in the environment. In this study, toxicity analyzes were conducted to determine the adverse effects of PP on Daphnia magna (D. magna) and Saccharamyces cerevisiae (S. cerevisiae). For this purpose, D. magna juveniles ( $<24$ hours) were exposed to various PP concentrations ranging from very low concentration $(0.01 \mu \mathrm{M})$ to very high concentration $(500 \mu \mathrm{M})$ for 48 hours, and the effects of PP on survival were investigated and LC50 values were determined. PP concentations at $100 \mu \mathrm{M}$ and above were highly toxic to $D$. magna. $\mathrm{LC}_{50}$ values were $58 \mu \mathrm{M}$ and $49.3 \mu \mathrm{M}$ at 24 and $48 \mathrm{~h}$ exposures, respectively. Meanwhile, the effects of various PP concentrations $(10,50,100,400,800$ and $1000 \mu \mathrm{M}$ PP) on S. cerevisiae were determined using growth kinetics and inhibition levels as endpoints. While no effect on growth kinetics was observed at concentrations up to $100 \mu \mathrm{M}$ PP, higher concentrations resulted in significant decrease in growth kinetics of yeast cells. Cell inhibition increased with increase of PP concentrations. PP showed higher toxicity in D. magna compared to S. cerevisiae. Overall, this study provided important insight into the adverse effects of PP and demonstrated the need for further research to explore the molecular mechanism of parabens-associated toxicity.
\end{abstract}

Keywords: Propylparaben, toxicity, D. magna, S. cerevisiae, $\mathrm{LC}_{50}$

\section{GİRIŞ}

Parabenler, antimikrobiyal aktiviteye sahip mükemmel bir koruyucu olan p-hidroksibenzoik asidin alkil esterleridir ve ilaç, gıda ve kozmetik gibi çeşitli tüketici ürünlerinde küf ve mayaları kontrol etmek için kullanılmaktadır [1-4]. Her yıl dünya çapında yaklaşık 8000 ton paraben tüketilmekte olup bu bileşikler, üretimi ve bertarafı sırasında çevreye sızabilmektedir. Bu nedenle, düzenli depolama alanlarında, atık su arıtma tesislerinde ve kanalizasyon çamurunda tespit edilebilmektedirler [5]. Ayrıca, paraben ve metabolitleri hava, toz, 
atık su, yüzey suları, ve insan idrarı gibi yerlerde de tespit edilmiştir [1, 2]. Paraben maruziyeti, sindirim, inhalasyon veya deri absorpsiyon yoluyla gerçekleşebilmektedir [6]. Bununla birlikte, bu bileşiklerin çeşitli in vivo ve in vitro çalışmalarda endokrin bozucu aktiviteye sahip olduğu gösterilmiştir [2, 6-8]. Günümüzde, yüksek üretim kapasiteleri, sürekli kullanımları ve çevreden uzaklaştırma oranına kıyasla yüksek salınım oranları nedeniyle parabenler ekosisteme yönelik potansiyel bir tehdit oluşturmaya başlamıştır [2].

Propilparaben (PP), bu ailenin bir üyesi olup mikrobiyal büyümeyi engelleyerek çeşitli tüketici ürünlerin raf ömrünü uzatmak amacıyla yaygın bir şekilde kullanılmaktadır [9, 10]. PP, geniş bir $\mathrm{pH}$ aralığında stabil bir molekül olup suda yüksek bir çözünürlüğe sahiptir. Böylece sulu bir fazda etkili bir konsantrasyon seviyesine ulaşma potansiyeli taşımaktadır [11]. Aerobik koşullar altında biyolojik olarak kolayca parçalanabilir ve biyolojik birikim potansiyeli düşük - orta düzeydedir [12, 13]. PP'nin yaygın kullanımı, sucul ortamlarda tespit edilmesiyle sonuçlanmıştır. Bildirilen PP konsantrasyonları sırasıyla ham atık suda $\sim 20 \mu \mathrm{g} / \mathrm{L}$, arıtılmamış sızıntı sularında 1,82 $\mu \mathrm{g} / \mathrm{L}$, çamurda $174 \mathrm{ng} / \mathrm{g}$ kuru ağırlık (ka), çökeltilerde 60 ng/g ka'dır [1, 9, 14, 15]. Ayrıca içme suyundaki PP varlığı $9 \mathrm{ng} / \mathrm{L}$ seviyesinde belirlenmiştir [14].

Yapılan çalıșmalarda, PP'ye maruz kalmanın insan spermlerinin canlılığını değiştirdiği ve sıçanların ön midesinde hücre proliferasyonunu uyardığ gösterilmiştir [16, 17]. PP'nin erkek gök kuşağ1 alabalığı ve Japon pirinç balığında vitellojenin sentezini tetiklediği rapor edilmiştir [18, 19]. İplik kurdu (Caenorhabditis elegans) ile yapılan diğer bir çalışmada PP'nin konsantrasyona bağlı toksisite gösterdiği ve organizmanın boy uzunluğunu azalttığı ve üremeği tetiklediği bildirilmiştir [20]. Yakın zamanda yapılan bir başka çalışmada PP'nin konsantrasyona bağlı bir şekilde zebra balığında gelişim anomalilerine ve gen ekspresyon seviyelerinde değişimlere sebep olduğu tespit edilmiştir [21]. Çalışmamızda yer alan organizmalardan biri olan D. magna'da yapilan çalışmalarda da PP'nin artan konsantrasyonlarına bağlı olarak toksisite gösterdiği bildirilmiştir [22-24]. PP'nin in vivo ve in vitro etkileri geniş çapta incelenmesine rağmen, elde edilen veriler halen yetersiz ve/veya sonuçsuz kalmaktadır.

Daphnia magna (D. magna; su piresi), toksikolojik çalışmalarda önemli bir in vivo model organizma olup dünya çapında ekotoksikolojik testler için en yaygın kullanılan sistemlerden biridir [25]. D. magna, yosun, bakteri ve protozoaları besin olarak kullanırken balıklar için birincil yem olduğu için ekolojik besin ağlarında önemli bir tür olarak kabul edilir [26]. Bununla birlikte, Saccharomyces cerevisiae (S. cerevisiae; maya), yaşlanma, hücre döngüsü, nörodejeneratif hastalıklar, gen ekspresyonunun düzenlenmesi ve birçok farklı biyolojik süreci araştırmak için çeşitli çalışmalarda kullanılan ökaryotik bir model organizmadır [27]. S. cerevisiae basit büyüme koşullarına, hızlı üreme oranlarına sahiptir ve kolaylıkla manipüle edilebilir. Dahası, insanlar dahil yüksek ökaryotlarla birçok yapısal ve işlevsel benzerliği bulunmaktadır [28]. Bu nedenle, bu iki organizma potansiyel olarak kirleticilerin toksisitesinin altında yatan moleküler mekanizmaları ortaya çıkarmak ve daha yüksek ökaryotlardaki verileri tahmin etmek için kullanılabilir.

Bu çalışmada, PP'nin toksik etkilerini değerlendirmek için biyolojik model olarak kullanılan $D$. magna ve $\mathrm{S}$. cerevisiae kontrollü koşullar altında laboratuvarda PP'nin farklı konsantrasyonlarına maruz bırakılmıştır. Çalışmamızda PP'nin konsantrasyona bağlı olarak her iki organizmada da toksik olduğu, büyümeyi inhibe ettiği ve yüksek dozlarda öldürücü olduğu tespit edilmiştir.

\section{MATERYAL VE YÖNTEM}

\subsection{Materyal}

Bu çalışmada kullanılan propilparaben (PP; saflık - \% 98) Sigma-Aldrich'ten (St Louis, MO) satın alınmıştır. Maruziyet deneylerinde kullanılan konsantrasyonları elde etmek için PP, dimetilsülfoksit (DMSO; Sigma) içinde çözülmüştür. DMSO'nun deneylerdeki maksimum konsantrasyonu \% 0.1 olacak şekilde ayarlanmıştır.

\subsection{Yöntem}

\subsubsection{D. magna kültürü, bakımı ve maruziyeti}

PP'nin etkisini incelemek için Daphtoxkit (MicroBioTests Inc., Belçika) kullanılmıştır. D. magna yumurtaları musluk suyunda durulanarak aktive edilmiş ve ardından 6000 lüks sürekli aydınlatma altında ve $20-22{ }^{\circ} \mathrm{C}$ sicaklikta, standart suda $(67,75$ $\mathrm{mg} / \mathrm{L} \mathrm{NaHCO}_{3}, 294 \mathrm{mg} / \mathrm{L} \mathrm{CaCl}_{2}, 123,25 \mathrm{mg} / \mathrm{L} \mathrm{MgSO}_{4}$ ve $5,75 \mathrm{mg} / \mathrm{L} \mathrm{KCl}) \quad 72-90$ saat inkübe edilerek yumurtadan çıkmaları sağlanmıştır. Yumurtadan yeni çıkan yavrular $(<24$ saat), maruziyetten 2 saat önce Spirulina mikroalg süspansiyonu ile beslenmiştir.

\subsubsection{D. magna akut toksisite analizi}

Hayatta kalma deneyi için D. magna yavruları $(<24$ saat), her bir kuyuda 10-20 hayvan olmak üzere 6 kuyucuklu plakalarda (BD Falcon) PP'ye maruz bırakılmıştır. Her maruziyet üç tekrarlı olacak şekilde gerçekleştirilmiştir. D. magna, \% 0.1 DMSO (kontrol) veya $P P(0.01,0.1,1,5,10,25,50,100,250$, ve 500 $\mu \mathrm{M})$ içeren $10 \mathrm{~mL}$ standart suya maruz bırakılmıştır. 24 ve 48 saatlerde hayatta kalma oranları kayıt altına alınmıştır. Bir yavru, mikroskop ile incelemede, hareketsizleşmişse ve organ hareketi gözlenmemişse ölü kabul edilmiştir. Daha sonra, ölüm oranının \% 50 olduğu ( $\mathrm{LC}_{50}$ değerleri) PP konsantrasyonları $(\mu \mathrm{M})$ ve D. magna'nın ölüm oranı arasındaki ilişkiyi gösteren regresyon eğrileri kullanılarak belirlenmiştir. 


\subsubsection{S. cerevisiae suş, büyüme koşullarl ve PP maruziyeti}

S. cerevisiae BY4742 (Mat $\alpha$; his $3 \Delta 1$; leu $2 \Delta 0$; lys $2 \Delta 0$; ura3 $\Delta 0$ ) Euroscarf koleksiyonundan (Frankfurt, Almanya) temin edilmiştir. Aksi belirtilmedikçe, hücreler $30^{\circ} \mathrm{C}$ ve $180 \mathrm{rpm}$ orbital çalkalama ile kültüre edilmiştir. Ön kültürler için, $25 \mathrm{~mL}$ maya ekstraktı pepton - glikoz (yeast extract - peptone - glucose; YPD) ortamı (\% 2 [w/v] d-glikoz, \% 2 [w/v] pepton, \% $1[\mathrm{w} / \mathrm{v}]$ maya ekstraktı), YPD petri kabından elde edilen tek bir hücre kolonisi ile aşılanmış ve gece boyunca inkübe edilmiştir. Ön kültürün \% 1 'lik bir hacim fraksiyonu daha sonra 500 mL'lik erlenmeyer flasklarda bulunan $100 \mathrm{~mL}$ YPD sivı besiyerini aşılamak için kullanılmış ve 600 nm'de (OD600 nm) logaritmik fazın ortası olan optik yoğunluğa kadar büyütülmüştür. Daha sonra kültürlere çeşitli nihai konsantrasyonlarda $(10,50,100,400,800$ ve $1000 \mu \mathrm{M})$ PP eklenmiştir. Ortamdaki son DMSO konsantrasyonu, büyümeyi etkilemeyen $\% 0.1$ 'de (v/v) tutulmuştur. \% 0.1 (v/v) DMSO içeren, ancak PP içermeyen başka bir kültür ise kontrol olarak kullanılmıştır. Kullanılan PP konsantrasyonları için büyüme eğrisi, 600 nm'de optik yoğunluk izlenerek oluşturulmuştur.

\subsubsection{S. cerevisiae'da inhibisyon oranlarının belirlenmesi}

PP maruziyetinden sonra inhibisyon oranlarını belirlemek için hücre canlılığı, daha önceki çalışmalarda belirtilen yöntemlere göre metilen mavisi çözeltisi (\% 0.01 metilen mavisi, \% 2 sodyum sitrat) ile boyama yoluyla ölçülmüştür [29, 30]. Kısaca, 3 saat boyunca PP'ye maruz bırakılan maya kültürlerinden örnekler alınmış, uygun şekilde seyreltilmiş ve eşit hacimde metilen mavisi çözeltisi ile karıştırılmıştır. Ölü (mavi boyalı) ve canlı (boyanmamış) hücrelerin sayısı, karıştırıldıktan sonra 10 dakika içinde mikroskop altında belirlenmiştir. Maya büyümesinin inhibisyon yüzdesi (ölümcül olmayan PP dozları altında), $\left[\left(\mathrm{N}^{0}-\mathrm{N}^{\mathrm{x}}\right) / \mathrm{N}^{0}\right]$ x 100 olarak tanımlanmıştır. Burada $\mathrm{N}^{\mathrm{x}}$ ve $\mathrm{N}^{0}$, sırasıyla $\mathrm{X} \mu \mathrm{M}$ PP içeren ve içermeyen kültürlerdeki maya hücrelerinin sayısıdır [29].

\section{BULGULAR VE TARTISMA}

Ekosistemin antropojenik bileşiklerle kirlenmesi ve bu

A

24 saat

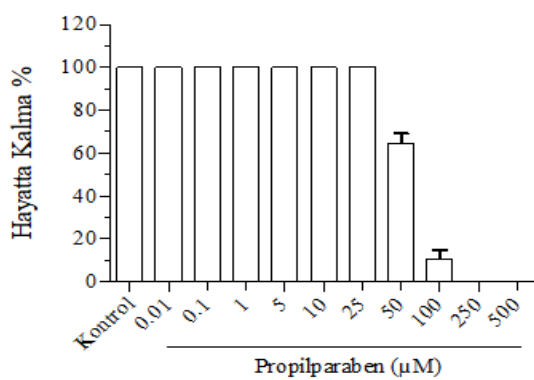

çevresel kirleticilerin canlılar üzerindeki potansiyel toksik etkileri gün geçtikçe toplumsal kaygıları arttırmaktadır. Parabenler dâhil birçok bileşik ve metabolitleri canlıları olumsuz etkileyebilir. $\mathrm{Bu}$ nedenle, en çok kullanılan parabenlerden bir tanesi olan PP'nin olası toksik etkileri iki önemli biyolojik model D. magna ve $S$. cerevisiae kullanılarak araştırılmıştır.

\subsection{PP'nin D. magna üzerindeki toksik etkileri}

D. magna üzerindeki etkisini belirlemek için, PP'nin çok düşük konsantrasyonundan $(0.01 \mu \mathrm{M})$, çok yüksek konsantrasyonuna $(500 \mu \mathrm{M})$ kadar çeşitli konsantrasyonlar kullanılarak akut toksisiteye neden olup olmadığını değerlendirmek için hayatta kalma testi yapılmıştır. D. magna'nın yumurtadan çıktıktan sonra 24 saatlik maruziyeti, 250 ve $500 \mu \mathrm{M}$ PP konsantrasyonlarında bütün yavruların ölümü ile sonuçlanmıştır (Şekil 1A). Bununla birlikte, aynı maruziyette 50 ve $100 \mu \mathrm{M}$ PP konsantrasyonlarında da önemli derecede toksik etki tespit edilmiş olup, hayatta kalma oranları sirasiyla \% 64.51 ve \% 10.52 olarak bulunmuştur (Şekil 1A). Diğer taraftan daha düşük PP konsantrasyonlarında 24 saatlik maruziyet sonunda herhangi bir etki gözlemlenmemiştir (Şekil 1A). Bununla birlikte, 48 saatlik maruziyet sonunda 50 ve $100 \mu \mathrm{M}$ PP konsantrasyonlarında hayatta kalma oranları sırasıyla \% 47.79 ve \% 5.13'e kadar düşmüştür (Şekil 1B). İlk 24 saat sonunda herhangi bir etki göstermeyen 10 ve $25 \mu \mathrm{M}$ PP konsantrasyonları ise 48 saat sonunda toksik etki göstermiş ve hayatta kalma oranları sirasıyla \%92.97 ve \% 93.65 olarak bulunmuştur (Şekil 1B). Elde edilen veriler PP'nin $D$. magna üzerindeki toksik etkisinin konsantrasyona bağlı olarak değiştiğini göstermiştir. Çalışmada elde edilen verilere benzer şekilde, daha önce Japon pirinç balığı embriyolarında yapılmış bir çalışmada, 4000 $\mu \mathrm{g} / \mathrm{L} \quad(\sim 22,2 \mu \mathrm{M})$ PP'nin embriyolarda anlaml seviyede bir ölüme neden olmadığı $(\% 7 \pm 2.6$ ölüm) gösterilmiştir [9]. Zebra balığı embriyolarında yapılan bir başka çalışmada ise $25 \mu \mathrm{M}$ ve üstü PP konsantrasyonlarının anlamlı düzeyde öldürücü olduğu belirlenmiştir [21]. Bu çalışma ve önceki çalışmalar birlikte ele alındığında, PP toksisitesine farklı türlerin duyarlılık seviyelerinin değişken olabileceğini göstermektedir.

B

48 saat

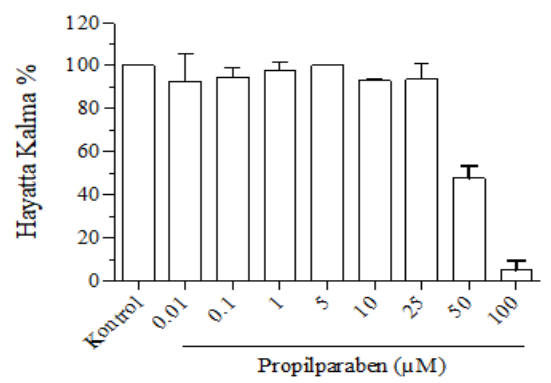

Şekil 1. PP'nin D. magna sağkalımı üzerindeki etkileri. Hayatta kalma oranlarının belirlenmesi için D. magna yavruları PP'ye maruz bırakılmıştır. (A) 24 saat, (B) 48 saat sonunda hayatta kalma seviyeleri. 
$\mathrm{LC}_{50}$ değeri, organizma popülasyonunun \% 50'sinin ölmesine sebep olan kimyasal konsantrasyonudur [23]. Çalışmada daha önce de belirtildiği gibi farklı konsantrasyonlardaki PP'ye maruz birakılan D. magna için $\mathrm{LC}_{50}$ değeri belirlenmeye çalışılmıştır. Elde edilen sonuçlara göre 24 ve 48 saatlik maruziyetler için $\mathrm{LC}_{50}$ değeri sırasıyla $58 \mu \mathrm{M}$ ve $49.3 \mu \mathrm{M}$ olarak bulunmuştur (Şekil 2A ve 2B). Bu sonuçlara göre maruziyet süresi arttıkça D. magna için PP'nin toksisite seviyesi artmakta ve buna paralel olarak $\mathrm{LC}_{50}$ değeri düşmektedir. Daha önce D. magna ile yapılan akut toksisite çalışmasında 24 saatlik maruziyet sonunda $\mathrm{LC}_{50}$ değeri yaklaşık $117.1 \mu \mathrm{M}$ olarak bulunmuştur [23]. D. magna ile yapılan bir başka çalışmada ise 48 saatlik akut toksisite maruziyeti sonunda $\mathrm{LC}_{50}$ değeri yaklaşık 68.3 $\mu \mathrm{M}$ olarak tespit edilmiştir [22]. Bu farklar, D. magna kaynağı ve deney ortamı, sıcaklık, kültür için kullanılan suyun kimyasal bileşimi ve besin kaynağı dahil maruz kalma koşullarının farklılığından kaynaklanıyor olabilir. Bununla birlikte, iplik kurdunda yapılan bir çalışmada 24 saatlik PP maruziyeti sonunda $\mathrm{LC}_{50}$ değeri $261.7 \mu \mathrm{M}$ olarak bulunmuştur [20]. Bulgular karşılaştırıldığında D. magna'nın iplik kurduna göre PP hassasiyeti daha yüksek olup, PP'nin türe bağlı etki seviyesinin değiştiği söylenebilir.

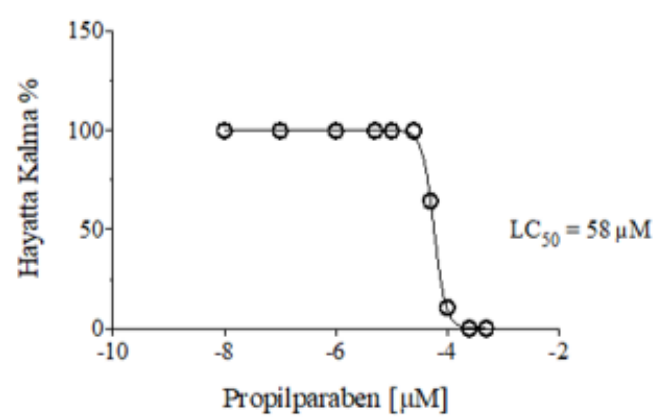

B

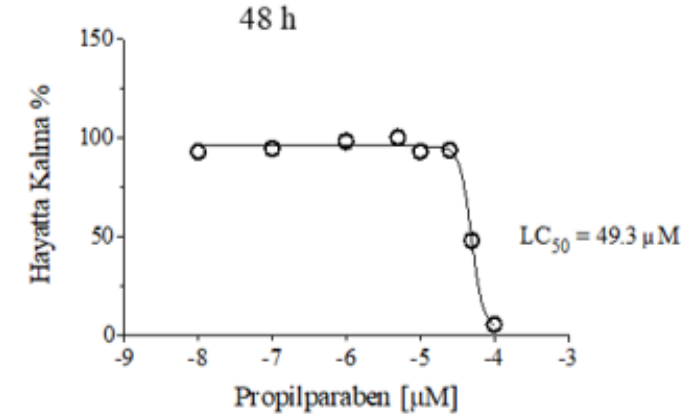

Şekil 2. D. magna için PP LC50 değerleri. D. magna yavruları PP'nin farklı konsantrasyonlarına maruz bırakılmış ve $\mathrm{LC}_{50}$ değerleri regresyon analizi ile belirlenmiştir. (A) 24 saat, (B) 48 saat için $\mathrm{LC}_{50}$ değerleri.

\subsection{PP'nin S. cerevisiae üzerindeki toksik etkileri}

PP'nin S. cerevisiae BY4742 suşu üzerindeki etkisini araştırmak için maya hücreleri PP'ye maruz bırakılarak inceleme altına alınmıştır. $\mathrm{Bu}$ analizler için maya kültürleri, logaritmik fazın ortasından başlayarak 3 saat boyunca PP'ye maruz bırakılmıştır. Maruz kalma süresi, maya hücrelerinin kimyasallara karşı moleküler cevaplarının tipik olarak maruziyetten birkaç saat sonra ortaya çıktığını gösteren önceki çalışmaların sonuçlarına dayanmaktadır [29, 31, 32].

PP'nin toksik seviyesini belirlemek için, maya hücrelerini çeşitli PP konsantrasyonlarına (10, 50, 100, 400, 800 ve $1000 \mu \mathrm{M}$ PP) maruz bırakılmış ve metilen mavisi çözeltisi ile boyama yöntemiyle hücre canlılığı ölçülmüştür. $100 \quad \mu \mathrm{M} \quad$ PP'ye kadar olan konsantrasyonlarda büyüme kinetiğinde (optik yoğunluk) etki gözlemlenmemiştir. Ancak daha yüksek konsantrasyonlarda konsantrasyon arttıkça büyüme kinetiğinin düşüş gösterdiği tespit edilmiştir (Şekil 3). Bunun tersine, hücre sayısı ölçümlerine bakıldığında en düşük konsantrasyondan itibaren konsantrasyondaki artışa paralel olarak inhibisyon seviyesinde bir artış (hücre sayısında düşüş) olduğu belirlenmiştir (Şekil 4A ve 4B). Elde dilen verilere bakıldığında en düşük konsatrasyon olan $10 \mu \mathrm{M}$ PP'de $\%$ inhibisyon gözlemlenirken, en yüksek konsantrasyon olan $1000 \mu \mathrm{M}$ PP'de ise \%72.1 inhibisyon tespit edilmiştir (Şekil 4B). Diğer taraftan kullanılan hiçbir konsantrasyonda anlamlı seviyede bir hücre ölümüne rastlanmazken $100 \mu \mathrm{M}$ PP üzeri konsantrasyonlarda birer hücre ölümü tespit edilmiştir (Şekil 4C). Çalışmada yer alan D. magna ve $S$. cerevisiae PP toksisitesi bakımından karşılaştırıldığında maya hücrelerinin çok daha dirençli olduğu söylenebilir. $100 \mu \mathrm{M}$ PP konsantrasyonun $D$. magna' da yüksek seviyede toksik olduğu (24 ve 48 saat sonunda hayatta kalma oranları sırasiyla $\% 10.52$ ve $\%$ 5.13) belirlenirken, ayn1 konsantrasyonun $S$. cerevisiae'de öldürücü olmadığı tespit edilmiştir (Şekil 1 ve 4). Bununla birlikte, D. magna ve birçok farklı organizma ile yapılan çalışmalar dikkate alındığında $[8$, 20-23] S. cerevisiae hücrelerinin PP toksisitesi karşısında yüksek bir toleransa sahip olduğu söylenebilir. Bu göreli yüksek PP toleransının altında yatan olası moleküler mekanizmalar arasında $S$. cerevisiae tarafindan geliştirilen adaptif mekanizmaların yer alabileceği düşünülmektedir. $S$. cerevisiae değişken çevresel ve fizyolojik koşullar altında işlev gören birçok gen duplikasyonuna sahiptir. $\mathrm{Bu}$ gen duplikasyonları merkezi metabolizmada yoğunlaşmış olup, merkezi metabolizmada yer alan metabolik yollar hücrenin canlılığını devam ettirmede diğer metabolik yollardan daha aktiftir. Ayrıca, maya hücrelerinde bulunan ve farklı stres koşullarında devreye giren alternatif sinyal yolları da bulunmaktadır [33]. Bununla birlikte, gen ve protein ekspresyonu gibi farklı son noktalarda analizler yaparak bu adaptif mekanizmaların PP toksisitesindeki etkin rollerinin tespit edilmesi gerekmektedir. 


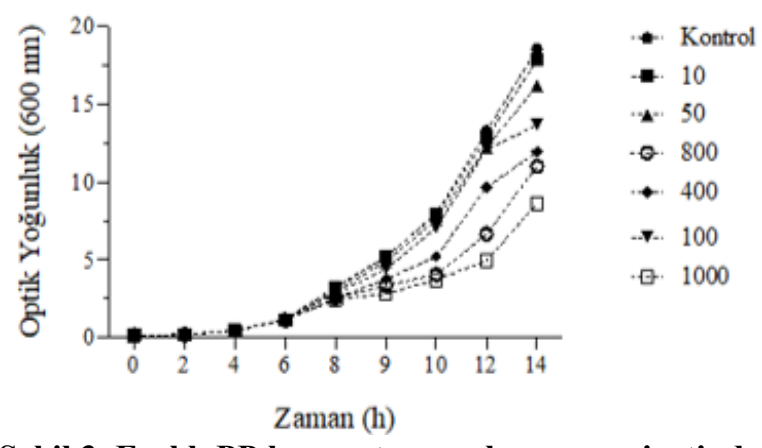

Şekil 3. Farklı PP konsantrasyonları maruziyetinde

S. cerevisiae BY4742 suşu büyüme kinetiği. Maya hücreleri çeşitli PP konsantrasyonlarına maruz bırakılmış ve 600 nm'de optik yoğunluk ölçülerek kaydedilmiştir.

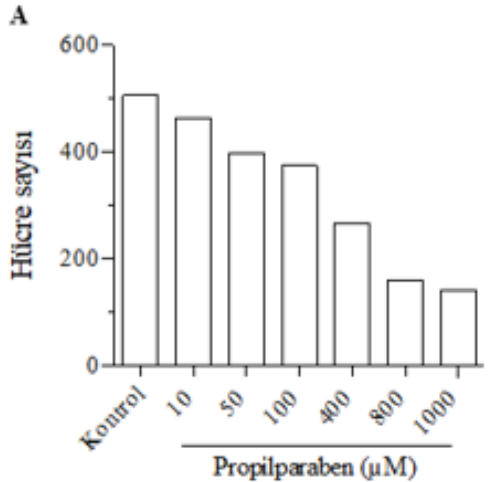

B

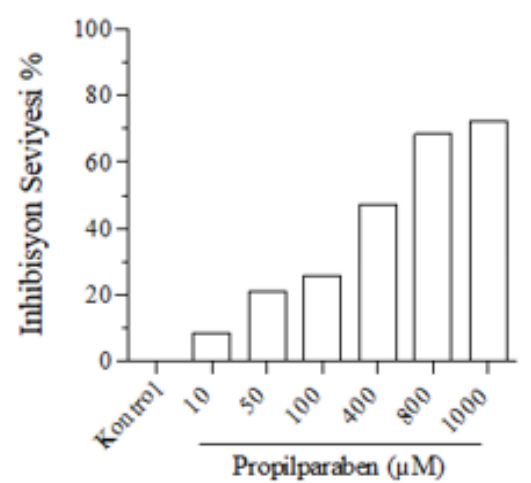

C

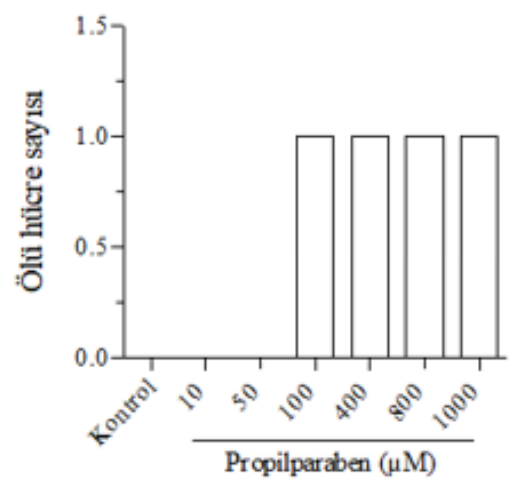

Şekil 4. PP maruziyetinin S. cerevisiae BY4742 suşu üzerindeki etkileri. (A) Hücre sayısı, (B) İnhibisyon seviyesi (\%), (C) Ölü hücre sayısı.

\section{SONUÇ}

Parabenler, ticari ürünlerde koruyucu olarak yaygın şekilde kullanılmaktadır. Bununla birlikte, toksisiteleri yeterli bir seviyede değerlendirilmemiştir. $\mathrm{Bu}$ çalışmada, iki model organizma $D$. magna ve $S$. cerevisiae'de en yaygın kullanılan parabenlerden biri olan PP'nin toksisitesi araştırılmıştır. Elde edilen veriler PP'nin ekosistemdeki canlılar için zararlı olabileceğini göstermektedir. PP, D. magna'da yüksek toksisite profili göstermiş, $S$. cerevisiae hücrelerinde önemli derecede inhibisyon etkisi yaratmıştır. Sonuçlar, PP'nin $S$. cerevisiae ile karşılaştırıldığında $D$. magna'da daha yüksek toksisiteye sahip olduğunu göstermiştir. Sonuç olarak, bu çalışmadaki bulgular, PP'nin konsantrasyona bağlı bir şekilde $D$. magna ve $S$. cerevisiae için toksik olduğunu göstermektedir. Ekosistemde parabenlerin seviyesi her geçen gün artmaktadır, bu nedenle kullanımlarını düzenlemek için etki mekanizmaları ayrıntılı olarak incelenmelidir. Bu kapsamda, bu çalışmada sunulan bilgiler, parabenlerin etkilerine ilişkin fikir vermektedir. Bununla birlikte, parabenlerin toksisitesine dair moleküler mekanizmaları ortaya çıkarmak için daha ileri çalışmalar yapılması gerekmektedir.

\section{TEŞEKKÜR}

$\mathrm{Bu}$ çalışma Marmara Üniversitesi Biyomühendislik Bölümü Moleküler Ekoloji Araştırma Grubu, Örebro Üniversitesi (İsveç), Yaşam Bilimleri Merkezi Moleküler Biyoloji Araştırma Grubu ve İskenderun Teknik Üniversitesi tarafından desteklenmiştir.

\section{KAYNAKLAR}

[1] Haman, C., Dauchy, X., Rosin, C. ve Munoz, J. F., (2015). Occurrence, fate and behavior of parabens in aquatic environments: a review. Water Research, 68, 111.

[2] Martín, J. M. P., Peropadre, A., Herrero, Ó., Freire, P. F., Labrador, V. ve Hazen, M. J., (2010). Oxidative DNA damage contributes to the toxic activity of propylparaben in mammalian cells. Mutation Research/Genetic Toxicology and Environmental Mutagenesis, 702, 86-91.

[3] Golden, R., Gandy, J. ve Vollmer, G., (2005). A review of the endocrine activity of parabens and implications for potential risks to human health. Critical Reviews in Toxicology, 35, 435-58.

[4] Calafat, A. M., Ye, X., Wong, L-Y., Bishop, A. M. ve Needham, L. L., (2010). Urinary concentrations of four parabens in the US population: NHANES 20052006. Environmental Health Perspectives, 118, 67985.

[5] Gao, Y., Ji, Y., Li, G. ve An, T., (2016). Theoretical investigation on the kinetics and mechanisms of hydroxyl radical-induced transformation of parabens and its consequences for toxicity: Influence of alkylchain length. Water Research, 91, 77-85.

[6] Kodani, S. D., Overby, H. B., Morisseau, C., Chen, J., Zhao, L. ve Hammock, B. D., (2016). Parabens inhibit fatty acid amide hydrolase: A potential role in 
paraben-enhanced 3T3-L1 adipocyte differentiation. Toxicology Letters, 262, 92-9.

[7] Kusk, K. O., Krüger, T., Long, M., Taxvig, C., Lykkesfeldt, A. E., Frederiksen, H. vd., (2011). Endocrine potency of wastewater: contents of endocrine disrupting chemicals and effects measured by in vivo and in vitro assays. Environmental Toxicology and Chemistry, 30, 413-26.

[8] Boberg, J., Taxvig, C., Christiansen, S. ve Hass, U., (2010). Possible endocrine disrupting effects of parabens and their metabolites. Reproductive Toxicology, 30, 301-12.

[9] González-Doncel, M., García-Mauriño, J. E., San Segundo, L., Beltrán, E. M., Sastre, S. ve Torija, C. F., (2014). Embryonic exposure of medaka (Oryzias latipes) to propylparaben: effects on early development and post-hatching growth. Environmental Pollution, 184, 360-9.

[10] Szeląg, S., Zabłocka, A., Trzeciak, K., Drozd, A., Baranowska-Bosiacka, I., Kolasa, A. vd., (2016). Propylparaben-induced disruption of energy metabolism in human HepG2 cell line leads to increased synthesis of superoxide anions and apoptosis. Toxicology in Vitro, 31, 30-4.

[11] Soni, M., Burdock, G., Taylor, S. ve Greenberg, N., (2001). Safety assessment of propyl paraben: a review of the published literature. Food and Chemical Toxicology, 39, 513-32.

[12] Butkovskyi, A., Rijnaarts, H., Zeeman, G. ve Leal, L. H., (2016). Fate of personal care and household products in source separated sanitation. Journal of Hazardous Materials, 320, 427-34.

[13] Siddique, S., Kubwabo, C. ve Harris, S. A., (2016). A review of the role of emerging environmental contaminants in the development of breast cancer in women. Emerging Contaminants, 2, 204-19.

[14] Carmona, E., Andreu, V. ve Picó, Y., (2014). Occurrence of acidic pharmaceuticals and personal care products in Turia River Basin: from waste to drinking water. Science of the Total Environment, 484, 53-63.

[15] Peng, X., Ou, W., Wang, C., Wang, Z., Huang, Q., Jin, J. vd., (2014). Occurrence and ecological potential of pharmaceuticals and personal care products in groundwater and reservoirs in the vicinity of municipal landfills in China. Science of the Total Environment, 490, 889-98.

[16] Shibata, M-A., Yamada, M., Hirose, M., Asakawa, E., Tatematsu, M. ve Ito, N., (1990). Early proliferative responses of forestomach and glandular stomach of rats treated with five different phenolic antioxidants. Carcinogenesis, 11, 425-9.

[17] Bao-Liang, S., Hai-Ying, L. ve Dun-Ren, P., (1989). In vitro spermicidal activity of parabens against human spermatozoa. Contraception, 39, 331-5.

[18] Inui, M., Adachi, T., Takenaka, S., Inui, H., Nakazawa, M., Ueda, M. vd., (2003). Effect of UV screens and preservatives on vitellogenin and choriogenin production in male medaka (Oryzias latipes). Toxicology, 194, 43-50.
[19] Pedersen, K. L., Pedersen, S. N., Christiansen, L. B., Korsgaard, B. ve Bjerregaard, P., (2000). The preservatives ethyl-, propyl- and butylparaben are oestrogenic in an in vivo fish assay. Pharmacology \& Toxicology, 86, 110-3.

[20] García-Espiñeira, M. C., Tejeda-Benítez, L. P. ve Olivero-Verbel, J., (2018). Toxic effects of bisphenol A, propyl paraben, and triclosan on Caenorhabditis elegans. International Journal of Environmental Research and Public Health, 15, 684.

[21] Bereketoglu, C. ve Pradhan, A., (2019). Comparative transcriptional analysis of methylparaben and propylparaben in zebrafish. Science of the Total Environment, 671, 129-39.

[22] Dobbins, L. L., Usenko, S., Brain, R. A. ve Brooks, B. W., (2009). Probabilistic ecological hazard assessment of parabens using Daphnia magna and Pimephales promelas. Environmental Toxicology and Chemistry, 28, 2744-53.

[23] Lee, J., Bang, S. H., Kim, Y-H. ve Min, J., (2018). Toxicities of four parabens and their mixtures to Daphnia magna and Aliivibrio fischeri. Environmental Health and Toxicology, 33.

[24] Terasaki, M., Makino, M. ve Tatarazako, N., (2009). Acute toxicity of parabens and their chlorinated by- products with Daphnia magna and Vibrio fischeri bioassays. Journal of Applied Toxicology, 29, 242-7.

[25] Jordão, R., Garreta, E., Campos, B., Lemos, M. F., Soares, A. M., Tauler, R. vd., (2016). Compounds altering fat storage in Daphnia magna. Science of the Total Environment, 545, 127-36.

[26] Colbourne, J. K., Pfrender, M. E., Gilbert, D., Thomas, W. K., Tucker, A., Oakley, T. H. vd., (2011). The ecoresponsive genome of Daphnia pulex. Science, 331, 555-61.

[27] Karathia, H., Vilaprinyo, E., Sorribas, A. ve Alves, R., (2011). Saccharomyces cerevisiae as a model organism: a comparative study. PloS One, 6:e16015.

[28] Duina, A. A., Miller, M. E. ve Keeney, J. B., (2014). Budding yeast for budding geneticists: a primer on the Saccharomyces cerevisiae model system. Genetics, 197, 33-48.

[29] Bereketoglu, C., Arga, K. Y., Eraslan, S. ve Mertoglu, B., (2017). Genome reprogramming in Saccharomyces cerevisiae upon nonylphenol exposure. Physiological Genomics, 49, 549-66.

[30] Winter, D., Podtelejnikov, A. V., Mann, M. ve Li, R., (1997). The complex containing actin-related proteins Arp2 and Arp3 is required for the motility and integrity of yeast actin patches. Current Biology, 7, 519-29.

[31] Gasch, A. P. ve Werner-Washburne, M., (2002). The genomics of yeast responses to environmental stress and starvation. Functional \& Integrative Genomics, 2, 181-92.

[32] Gil, F. N., Gonçalves, A. C., Jacinto, M. J., Becker, J. D. ve Viegas, C. A., (2011). Transcriptional profiling in Saccharomyces cerevisiae relevant for predicting alachlor mechanisms of toxicity. Environmental Toxicology and Chemistry, 30, 2506-18. 
[33] Maltsev, N., Glass, E. M,, Ovchinnikova, G. ve Gu, Z., (2005). Molecular mechanisms involved in robustness of yeast central metabolism against null mutations. Journal of Biochemistry, 137, 177-87. 